Article

\title{
Application of the HPLC Method in Parenteral Nutrition Assessment: Stability Studies of Ondansetron
}

\author{
Szymon Tomczak*(D), Vera Radwan (D), Anna Jelińska and Maciej Stawny $\mathbb{C}$ \\ Department of Pharmaceutical Chemistry, Poznan University of Medical Sciences, 6 Grunwaldzka, \\ 60-780 Poznań, Poland; vbazradwan@gmail.com (V.R.); ajelinsk@ump.edu.pl (A.J.); mstawny@ump.edu.pl (M.S.) \\ * Correspondence: szymon.tomczak@ump.edu.pl; Tel.: +48-618-546-617
}

\begin{abstract}
Ondansetron (OND) is a serotonin type 3 receptor antagonist that exhibits antiemetic activity From the clinical point of view, vomiting and nausea prevention is an important task. Anticancer treatment and recovery impact the patient's overall state by affecting appetite, well-being, and physical activity, and consequently, nutrition quality. Depending on the patient's indication and condition, parenteral nutrition is administered to meet full nutritional requirements. In addition, antiemetic drugs can be added to the parenteral nutrition ( $\mathrm{PN}$ ) admixture to treat chemo- or radio-therapy-induced nausea and vomiting. However, adding any medication to the PN admixture can result in the instability of the composition in the overall admixture. This study aimed to develop the HPLC method of determination of OND in Lipoflex special, one of the most popular, ready-to-use PN admixtures. The proposed HPLC method and the sample preparation procedure were suitable for analyzing OND in PN admixture stored under various conditions, such as exposure to sunlight and temperature. It was found that the decomposition of OND during the seven-day storage did not exceed 5\% and did not depend on external factors. Based on the conducted research, it is recommended to add OND to Lipoflex special, and it is possible to store such an admixture for seven days.
\end{abstract}

Keywords: drug determination; parenteral nutrition; stability study; ondansetron; HPLC

Jelinska, A.; Stawny, M. Application of the HPLC Method in Parenteral Nutrition Assessment: Stability Studies of Ondansetron. Processes 2021, 9, 453. https://doi.org/ $10.3390 /$ pr9030453

Academic Editors: Malgorzata Starek and Monika Dąbrowska

Received: 31 January 2021

Accepted: 25 February 2021

Published: 3 March 2021

Publisher's Note: MDPI stays neutral with regard to jurisdictional claims in published maps and institutional affiliations.

Copyright: (c) 2021 by the authors. Licensee MDPI, Basel, Switzerland. This article is an open access article distributed under the terms and conditions of the Creative Commons Attribution (CC BY) license (https:// creativecommons.org/licenses/by/ $4.0 /)$

\section{Introduction}

Ondansetron (OND) is a serotonin (5-hydroxytryptamine) type 3 receptor antagonist that exhibits antiemetic activity. The drug belongs to a carbazole derivative containing nitrogen and carbon rings [1]. The chemical structure is presented in Figure 1. It is structurally similar to serotonin, which allows it to bind selectively to the 5- $\mathrm{HT}_{3}$ receptors. OND is indicated as an effective antiemetic agent and is used for the prevention of nausea and vomiting in a variety of situations, including chemo- and radiotherapy, postoperative and pregnancy-induced nausea and vomiting [2,3]. From the clinical point of view, vomiting and nausea prevention is an important task. Anticancer treatment and recovery impact the patient's overall state by affecting appetite, well-being, physical activity, and consequently, nutrition quality. There are situations when malnutrition negates recovery prospects, because therapy has to be postponed due to the patient's condition. Therefore, proper nutrition is key to successful treatment. As far as signs of malnutrition or body mass loss are concerned, each may indicate the onset of cancer and concern healthcare professionals, since a lack of nutritional intervention may compromise the patient's condition and negatively influence prognosis. When malnutrition occurs, clinical nutrition remains necessary to support the recovery process. Depending on the state of the patient's health and resulting nutritional needs, it is necessary to administer either oral (regular or therapeutic diet), enteral, or parenteral nutrition (EN or PN) [4,5]. Nutritional treatment of severely malnourished patients has become routine in most modern-day hospitals. Depending on th e patient's indication and condition, parenteral nutrition is administered to meet full nutritional requirements. For instance, cancer patients receiving anticancer therapy such as chemotherapy or radiotherapy cannot eat food enterally due to consistent nausea and 
vomiting from the anticancer drugs. Therefore, parenteral nutrition can be administered to provide nutritional support in these types of patients. Antiemetic drugs, such as OND, can also be added to the PN admixture to treat chemo- or radiotherapy-induced nausea and vomiting. The addition of OND to the parenteral nutrition admixture can reduce the risk of catheter-related infections. However, adding any drug to the parenteral nutrition admixture can result in the instability of the admixture's overall composition.

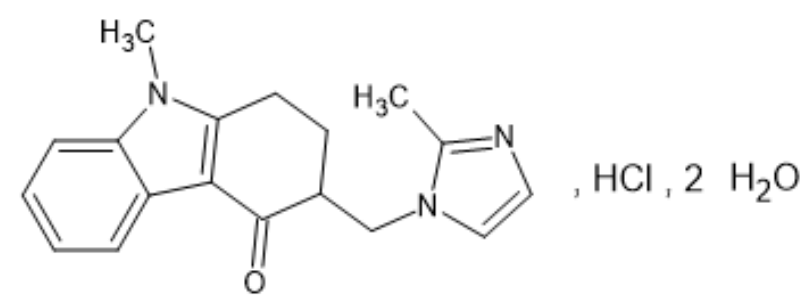

Figure 1. Ondansetron hydrochloride dihydrate-chemical structure.

PN admixture consists of various ingredients of high chemical reactivity (water, glucose, amino acids, lipids, trace elements, electrolytes, and vitamins) co-existing in one container. It is important to note that the $\mathrm{PN}$ admixture is an oil-in-water emulsion, which explains its thermodynamic sensitivity. The physicochemical compatibility of PN admixtures is another vital feature in the clinical point of view. Hospitalized patients often receive drugs via an intravenous route alongside nutritional supplementation. An additional challenge then results from the need to ensure an appropriate therapy, especially when several drugs are administered simultaneously [6].

The method of high-performance liquid chromatography (HPLC) has been successfully used in the analysis of amino acids and vitamins added to the PN admixtures. Vazquez et al. [7] developed the simultaneous determination of thirteen vitamins using the HPLC-UV-MS-MS method. The need for tandem mass spectrometry was due to the UV detector's low selectivity and the lack of a suitable chromophore for some vitamins, such as pantothenic acid. Ribeiro et al. [8] examined vitamins B1 and B6 by HPLC using a photodiode array detector. These researchers used fluorimetry to determine vitamin $\mathrm{B} 2$, and the vitamin $\mathrm{C}$ content was determined by iodometric titration. HPLC was also used to determine cocarboxylase [9], vitamins A and E [10], and dehydroascorbic acid [11]. The methods of chromatographic separation and determination of vitamins B1 [12,13] and C [14] and drugs, such as ranitidine [13], linezolid [15], cefepime [16], ceftazidime [17], ampicillin [18], and ciprofloxacin [19] in PN admixtures were also described.

Several bioanalytical methods have been reported in the literature for the quantification of OND, for example, spectrophotometric [20] and more popular liquid chromatography with UV [21-24] or MS [25-29] detection. Raza et al. [20] estimated drug concentration in bulk material using the spectrophotometry method. Numerous papers described OND determination in biological matrixes [26,29], i.e., human plasma or animal tissues in rats [22,25], cats [27], and dogs [30]. Investigations on the determination of OND, together with other drugs in infusion fluids, constitute a separate part. Chen et al. [24] developed and validated the HPLC-DAD (diode array detector) method for the simultaneous quantification of dexamethasone sodium phosphate, OND, granisetron, tropisetron, and azasetron hydrochlorides in infusion samples. Espinosa-Bosch et al. [31] evaluated the stability and the compatibility of haloperidol and OND when stored in elastomeric infusors at two temperatures (25 and $37^{\circ} \mathrm{C}$ ). In 1995, Kirkham et al. [32] described determination of OND in PN admixtures, but in their paper, no details are stated about sample isolation and method validation.

To the best of our knowledge, the determination of OND in Lipoflex special, one of the most popular ready-to-use PN admixtures, has not yet been reported. This lack of scientific information about the stability of OND in such PN admixtures prompted us to develop and optimize the procedure of sample preparation, validate the HPLC method, 
and perform the stability assessment of OND stored at different temperatures $(4 \pm 2$ and $\left.23 \pm 2{ }^{\circ} \mathrm{C}\right)$, with or without sunlight exposure.

\section{Materials and Methods}

\subsection{Materials}

The OND (Ondansetron $2 \mathrm{mg} / \mathrm{mL}$ solution for injection or infusion, Accord Healthcare, Harrow, UK) was added in the maximum daily dose $(32 \mathrm{mg})$ to the Lipoflex special $1250 \mathrm{~mL}$ (B. Braun, Melsungen AG, Melsungen, Germany).

The chemicals used to prepare the mobile phase for HPLC (sodium dihydrogen phosphate monohydrate, and acetonitrile) and reagents used in forced degradation studies (sodium hydroxide, hydrochloric acid, and 3\% hydrogen peroxide) were delivered by Avantor Performance Materials Poland S.A., Gliwice, Poland.

\subsection{Development of Sample Preparation Procedure}

From an analytical point of view, it is necessary to remove the lipid phase before injecting the sample into the chromatographic column. For this purpose, a sample preparation procedure was developed. The proportions of PN admixture and organic solvent and the time of shaking and centrifuging the samples were modified.

The following combinations of experimental conditions were tested: different volumes of n-hexane (1, 2, 3, and $5 \mathrm{~mL})$, different times of shaking $(5,10,15$, or $20 \mathrm{~min})$ at $250 \mathrm{rpm}$, and different times of centrifuging $(15,20,25$, or $30 \mathrm{~min})$ at $5800 \mathrm{rpm}$.

\subsection{Chromatografic Condition}

The HPLC analysis was performed on an Agilent Technologies 1220 Infinity LC chromatograph (Santa Clara, CA, United States) with a binary pump, a DAD detector, an autosampler, and a column oven. We adopted the literature method [33], which was dedicated to analyzing impurities in drug products and raw materials. In our work, we had a complex matrix containing numerous ingredients. As a result, we were obliged to revalidate this method to perform OND determination in parenteral nutrition admixtures. In our procedure, we additionally thermostated the column, whereas this condition is not described in the European Pharmacopoeia. The mobile phase composition, stationary phase, volume of injection, and flow rate were in agreement with the literature data. The mobile phase consisted of acetonitrile HPLC grade (phase A) and $2.8 \mathrm{~g} / \mathrm{L}$ solution of sodium dihydrogen phosphate monohydrate, adjusted to $\mathrm{pH}$ of 5.4 with $12 \%$ orthophosphoric acid (phase B). Phases A and B were mixed in a ratio of 20:80 (V/V), the flow rate was $1.5 \mathrm{~mL} / \mathrm{min}$, and the injection volume was $20 \mu \mathrm{L}$. The stationary phase was spherical nitrile silica gel for chromatography (ZORBAX Eclipse XDB-CN $5 \mu \mathrm{m}$, Manufacturer: Agilent Technologies, $4.6 \times 250 \mathrm{~mm}$ ). The analyses were performed at $25 \pm 1{ }^{\circ} \mathrm{C}$ with monitoring of the signal at $216 \mathrm{~nm}$. The run-time of the experiment was 15 minutes.

\subsection{Forced Degradation Study}

A forced degradation study was performed to observe any significant degradation peaks of OND on chromatograms. The following stress factors were used:

- Acidic hydrolysis: $0.1 \mathrm{~mol} / \mathrm{L}$ of hydrochloric acid;

- Basic hydrolysis: $0.1 \mathrm{~mol} / \mathrm{L}$ of sodium hydroxide;

- Oxidative stress: $3 \%$ hydrogen peroxide;

- High temperature: OND heated to boiling point.

The OND in Lipoflex special, at a concentration of $0.0266 \mathrm{mg} / \mathrm{mL}$, was treated with the reagents mentioned above or heated to high temperature for 5 minutes and was then cooled. Afterwards, the obtained samples were injected into the chromatographic column. 


\subsection{Method Validation}

\subsubsection{Linearity}

The linearity was evaluated using measurements of six concentrations of the analyte. The concentrations of OND in the PN admixture ranged from 0.0066 to $0.04 \mathrm{mg} / \mathrm{mL}$. The samples were prepared by adding $0.33,0.67,1.00,1.33,1.67$, and $2.00 \mathrm{~mL}$ of OND into a $100 \mathrm{~mL}$ volumetric flask to achieve the final concentrations. Each amount of OND was diluted to $100 \mathrm{~mL}$ with the PN admixture. Three separate series of calibration standards were prepared to establish linearity. The results were examined for a linear relationship by plotting the analyte $P_{i}$ versus the corresponding concentrations, followed by ordinary least squares linear regression (OLS) and calculating the slope, intercept, and correlation coefficient.

To define the fit of the model, the F-test and the residual plots were evaluated, and the homoscedasticity of the data was determined following the previously used method [18]. Briefly, in case of the lack of homogeneity, the homoscedasticity was evaluated by plotting graphs of the residuals vs. concentration. Then, weighted least squares regression (WLS) was utilized to calculate the regression line. In the course of calculations, the appropriate weighting factors, $\mathrm{w}_{\mathrm{i}}$, i.e., $\frac{1}{\mathrm{y}^{0.5}}, \frac{1}{\mathrm{y}}, \frac{1}{\mathrm{y}^{2}}, \frac{1}{\mathrm{x}^{0.5}}, \frac{1}{\mathrm{x}}$, and $\frac{1}{\mathrm{x}^{2}}$, were used. Subsequently, the sums of the percentage relative errors $\left(\sum \% \mathrm{RE}\right)$ were calculated for each model to determine the best-fitting weighted regression line.

\subsubsection{Precision and Repeatability}

The repeatability (intra-day precision) and intermediate precision (inter-day precision) were calculated by analyzing nine OND samples at concentrations of $0.0266 \mathrm{mg} / \mathrm{mL}$. The results were expressed as the relative standard deviation (RSD). The intra-day precision was performed on the same day, and another analyst repeated the inter-day precision the next day.

\subsubsection{Accuracy}

The accuracy was performed to obtain the closeness of the agreement between the expected value and the determined value. Nine different samples of OND at a concentration of $0.0266 \mathrm{mg} / \mathrm{mL}$ were analyzed. The results were expressed as a relative error $\left(\varepsilon_{\mathrm{r}}\right)$ calculated by the relationship between the experimental concentration $\left(\mathrm{C}_{\exp }\right)$ and the theoretical concentration $\left(C_{\text {theoret }}\right)$ and defined as a percentage:

$$
\frac{C_{\text {theoret }}-C_{\text {exp }}}{C_{\text {theoret }}} \times 100 \%
$$

\subsubsection{Limit of Determination (LOD) and Limit of Quantification (LOQ)}

The LOD and LOQ parameters were determined from the OLS and WLS equations. LOD was calculated as $3.3 \mathrm{Sy} / \mathrm{a}$, and LOQ as $10 \mathrm{Sy} / \mathrm{a}$, where Sy is a standard error and a is the slope of the corresponding calibration curve.

\subsection{Stability Study}

The samples of Lipoflex special containing OND were stored at three different conditions: $4 \pm 2{ }^{\circ} \mathrm{C}$ with light protection, $23 \pm 2{ }^{\circ} \mathrm{C}$ with light protection, and $23 \pm 2{ }^{\circ} \mathrm{C}$ without light protection. HPLC analysis was performed on the day of the sample preparation and also $24,48,72,92,120$, and $144 \mathrm{~h}$ after preparation. Every $24 \mathrm{~h}$, a volume of $3.0 \mathrm{~mL}$ was withdrawn from each PN admixture and then used for chemical stability tests.

\subsection{Physicochemical Assessment of PN Admixture}

Stability studies were performed by analyzing the physicochemical assessment of the $\mathrm{PN}$ admixture. The osmolality, $\mathrm{pH}$, zeta potential, and size of the lipid emulsion particle, expressed as mean emulsion droplet diameter (MDD), were performed. The measurements were in accordance with the methodology described previously [34,35]. 


\section{Results}

Lipoflex special showed appropriate parameters for intravenous administration. Directly after activating the chambers containing amino acids, glucose, and fat emulsion and after seven days of storage at $4 \pm 2{ }^{\circ} \mathrm{C}$ temperature, the physicochemical parameters were in the following ranges: potential zeta from -5.82 to $-5.90 \mathrm{mV}$, the MDD from 247.2 to $251.9 \mathrm{~nm}, \mathrm{pH}$ from 5.50 to 5.53 , and osmolality from 1997 to $1988 \mathrm{mOsm} / \mathrm{kg}$. The addition of a $32 \mathrm{mg}$ dose of OND to Lipoflex special $1250 \mathrm{~mL}$ resulted in a $5.5 \%$ reduction in osmolality and an increase in the potential zeta by $15 \%$. The particle size of lipid emulsion and $\mathrm{pH}$ did not change statistically after adding OND. On the seventh day of storage, Lipoflex special with OND showed all parameters in a similar range as the reference sample (Lipoflex special without OND on the seventh day of storage). The PN admixture's physicochemical characteristics without and with the addition of OND are presented in Table 1. The samples were stored at $4 \pm 2{ }^{\circ} \mathrm{C}$ without light exposure.

Table 1. Physicochemical characteristic of Lipoflex special with and without ondansetron (OND).

\begin{tabular}{ccccc}
\hline \multirow{2}{*}{ Parameter } & \multicolumn{2}{c}{ Lipoflex Special } & \multicolumn{2}{c}{ Lipoflex Special + OND } \\
\cline { 2 - 5 } & 1 Day & 7 Days & 1 Day & 7 Days \\
\hline Zeta Potential $(\mathrm{mV})$ & $-5.82 \pm 0.27$ & $-5.90 \pm 0.42$ & $-4.92 \pm 0.10$ & $-5.57 \pm 0.27$ \\
\hline MDD $(\mathrm{nm})$ & $247.2 \pm 4.1$ & $251.9 \pm 4.3$ & $246.6 \pm 3.2$ & $253.3 \pm 5.8$ \\
\hline $\mathrm{pH}$ & $5.50 \pm 0.00$ & $5.53 \pm 0.00$ & $5.50 \pm 0.00$ & $5.52 \pm 0.01$ \\
\hline $\begin{array}{c}\text { Osmolality } \\
(\mathrm{mOsm} / \mathrm{kg})\end{array}$ & $1997 \pm 3$ & $1988 \pm 1$ & $1886 \pm 33$ & $1967 \pm 13$ \\
\hline
\end{tabular}

The HPLC method was used to determine the OND content in Lipoflex special. A total of $3 \mathrm{~mL}$ of Lipoflex special (reference sample) and Lipoflex special containing OND were mixed with n-hexane, shaken, and centrifuged in order to break up the lipid emulsion. Several variants of phase separation were tested (Table 2). The optimal combination with n-hexane in the ratio of 1:1 was shaken for $15 \mathrm{~min}$ and centrifuged for $30 \mathrm{~min}$ at $5800 \mathrm{rpm}$. At this ratio, the emulsion is broken and recovery is high. Differences in recovery between 3 and $5 \mathrm{~mL}$ are so close that we decided to use less volume of organic solvent to reduce waste volume and environmental footprint. The obtained supernatant was filtered and injected into the HPLC column. The chromatographic analysis of OND and Lipoflex special components was established for $15 \mathrm{~min}$. The retention time ( $\left.t_{R}\right)$ of OND was $9.4 \pm 0.1 \mathrm{~min}$ (Figure 2B).

Table 2. Recovery of OND in the optimization of the sample preparation process.

\begin{tabular}{|c|c|c|c|}
\hline No. & Separation Cor & & Recovery (\%) \\
\hline \multirow{3}{*}{1} & n-hexane volume (mL) & 1.0 & \multirow{3}{*}{75.2} \\
\hline & Shaking time (min) & 15 & \\
\hline & Centrifugation time (min) & 30 & \\
\hline \multirow{3}{*}{2} & n-hexane volume (mL) & 2.0 & \multirow{3}{*}{77.1} \\
\hline & Shaking time (min) & 15 & \\
\hline & Centrifugation time (min) & 30 & \\
\hline \multirow{3}{*}{3} & n-hexane volume (mL) & 3.0 & \multirow{3}{*}{82.2} \\
\hline & Shaking time (min) & 15 & \\
\hline & Centrifugation time (min) & 30 & \\
\hline \multirow{3}{*}{4} & n-hexane volume (mL) & 5.0 & \multirow{3}{*}{82.6} \\
\hline & Shaking time (min) & 15 & \\
\hline & Centrifugation time (min) & 30 & \\
\hline
\end{tabular}


Table 2. Cont.

\begin{tabular}{|c|c|c|c|}
\hline No. & \multicolumn{2}{|c|}{ Separation Condition } & Recovery (\%) \\
\hline \multirow{3}{*}{5} & n-hexane volume (mL) & 3.0 & \multirow{3}{*}{81.7} \\
\hline & Shaking time (min) & 5 & \\
\hline & Centrifugation time (min) & 30 & \\
\hline \multirow{3}{*}{6} & n-hexane volume (mL) & 3.0 & \multirow{3}{*}{81.8} \\
\hline & Shaking time (min) & 10 & \\
\hline & Centrifugation time (min) & 30 & \\
\hline \multirow{3}{*}{7} & n-hexane volume (mL) & 3.0 & \multirow{3}{*}{81.6} \\
\hline & Shaking time (min) & 20 & \\
\hline & Centrifugation time (min) & 30 & \\
\hline \multirow{3}{*}{8} & n-hexane volume (mL) & 3.0 & \multirow{3}{*}{80.8} \\
\hline & Shaking time (min) & 15 & \\
\hline & Centrifugation time (min) & 15 & \\
\hline \multirow{3}{*}{9} & n-hexane volume (mL) & 3.0 & \multirow{3}{*}{82.0} \\
\hline & Shaking time (min) & 15 & \\
\hline & Centrifugation time (min) & 20 & \\
\hline \multirow{3}{*}{10} & n-hexane volume (mL) & 3.0 & \multirow{3}{*}{82.1} \\
\hline & Shaking time (min) & 15 & \\
\hline & Centrifugation time (min) & 25 & \\
\hline
\end{tabular}

A

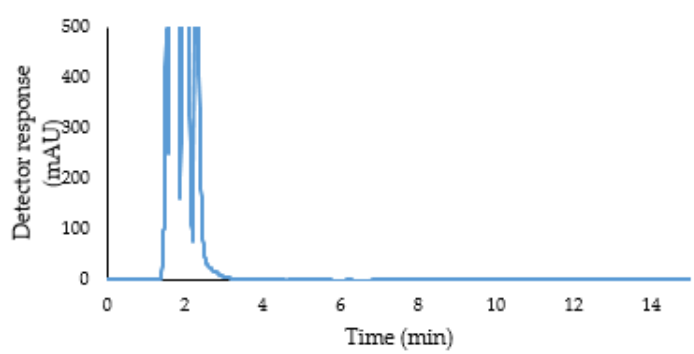

B

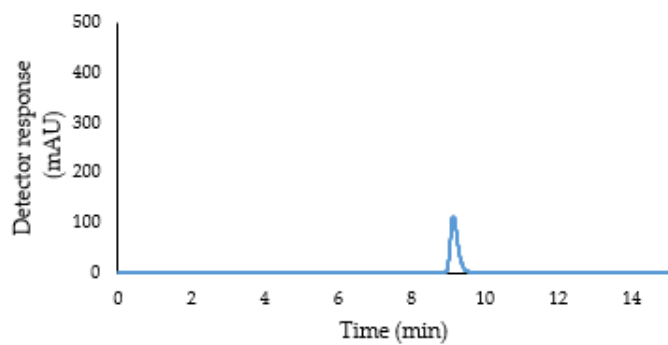

C

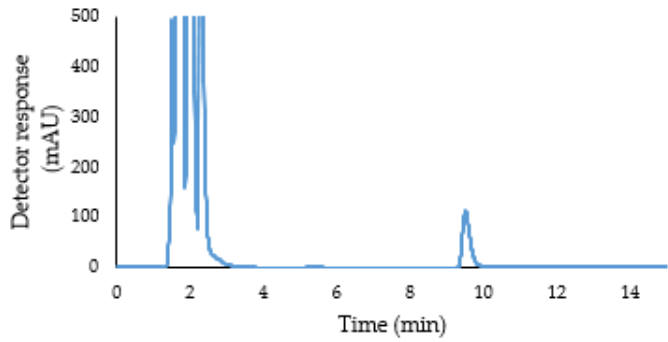

Figure 2. Chromatograms of Lipoflex special without OND (A), ondansetron (B), and Lipoflex special with OND (C). 
Following the ICH guidelines for analytical method validation (Q2(R1)) [36], both the forced degradation study (acidic and basic hydrolysis, oxidative stress, and high-temperature treatment) and validation (including method selectivity, precision, accuracy, and linearity) were determined. The limit of detection and quantification were also calculated.

As presented in Figure 3, OND is prone to degradation in the used stress factors. Under acidic hydrolysis, one additional peak was observed at $6.09 \mathrm{~min}$, and during basic hydrolysis of OND, three peaks were detected at $4.56 \mathrm{~min}, 6.09 \mathrm{~min}$, and $6.56 \mathrm{~min}$. A lower peak of OND was observed during the oxidative stress test, the potential degradation product interference with PN admixture compounds retention peaks. No significant peaks were identified during the high-temperature treatment of OND.

A

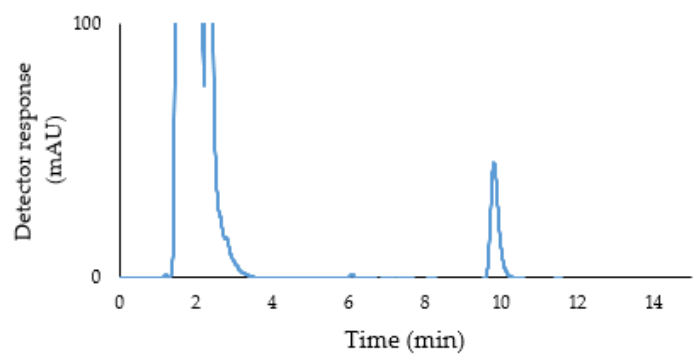

C

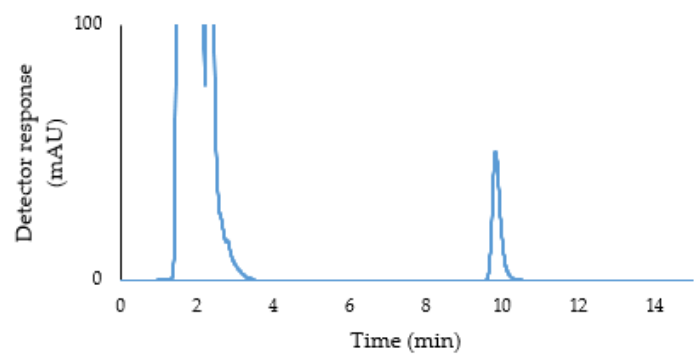

B

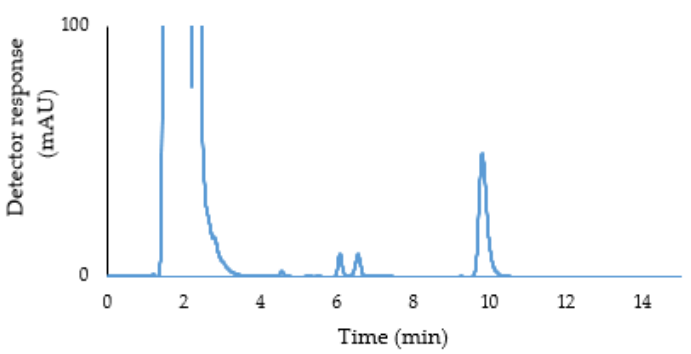

D

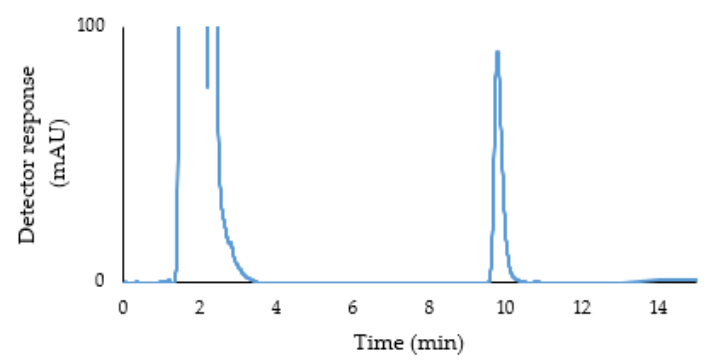

Figure 3. The HPLC chromatograms of forced degradation test. (A): $0.1 \mathrm{~mol} / \mathrm{L}$ hydrochloric acid, (B): $0.1 \mathrm{~mol} / \mathrm{L} \mathrm{of} \mathrm{sodium}$ hydroxide, (C): oxidative stress: 3\% hydrogen peroxide, (D): high temperature.

The HPLC method used in this study proved selective, because the OND peak on chromatograms (Figures 2 and 3) was well separated from the remaining ingredients of the Lipoflex special and its degradation products. The method was linear in the concentration range from 0.0066 to $0.0400 \mathrm{mg} / \mathrm{mL}$. Moreover, the relationship between the obtained signal and OND concentration, calculated by ordinary least squares regression (OLS), was characterized by a high correlation coefficient $(\mathrm{r}=0.9995)$. The following equation: $\mathrm{Pi}=68427 \times$ conc $-29.11,(n=18)$, where $\mathrm{Pi}$ is peak area and conc is OND concentration, described this relationship.

The homoscedasticity test of the data was performed to evaluate the fit of the OLS model. The $F_{\text {calc }}=12,742$ was greater than the $F_{\text {crit }}$. The residues widely distributed around the concentration axis suggested the heteroscedasticity of the data and the need to use the weighted least squares regression (WLS) to calculate the weighted regression parameters. To convert the regression equation to the weighted regression equation, six empirical weights, $\frac{1}{y^{0.5}}, \frac{1}{y}, \frac{1}{y^{2}}, \frac{1}{x^{0.5}}, \frac{1}{x}$, and $\frac{1}{x^{2}}$, were used. Table 3 provides the equation coefficients slope (a), intercept (b), and correlation coefficient (r) for each weighting model. The best-fitting model was determined by comparing the distribution of percentage relative error (\%RE) and the sums of percentage relative errors $\left(\sum \% R E\right)$ (presented in Table 3$)$. The smallest $\sum \% \mathrm{RE}=0.089$ was observed for $\mathrm{w}_{\mathrm{i}}=\frac{1}{\mathrm{y}}$ (Table 3 ). The same model also exhibited the best \%RE distribution and, thus, reflected the relationship between the detector signal and concentration in the best manner. 
Table 3. Regression parameters of the analytical curve and sums of the relative errors ( $\Sigma \% \mathrm{RE})$.

\begin{tabular}{cccccc}
\hline & $\mathbf{w}_{\mathbf{i}}$ & $\mathbf{a}$ & $\mathbf{b}$ & $\mathbf{r}$ & $\sum \% \mathbf{R E}$ \\
\hline $\begin{array}{c}\text { Ordinary } \\
\text { Least } \\
\text { Squares }\end{array}$ & 1 & 70.412 & -29.11 & 0.9995 & -3.37 \\
\hline & $\frac{1}{\mathrm{y}^{0.5}}$ & 70.226 & -24.70 & 0.99946 & -1.26 \\
\cline { 2 - 6 } & $\frac{1}{\mathrm{y}}$ & 70.011 & -20.29 & 0.99945 & 0.089 \\
\cline { 2 - 6 } $\begin{array}{c}\text { Weighted } \\
\text { Least } \\
\text { Squares }\end{array}$ & $\frac{1}{\mathrm{y}^{2}}$ & 69.490 & -12.49 & 0.99936 & -1.01 \\
\cline { 2 - 6 } & $\frac{1}{\mathrm{x}^{0.5}}$ & 70.222 & -24.35 & 0.99946 & -0.83 \\
\cline { 2 - 6 } & $\frac{1}{\mathrm{x}}$ & 70.006 & -19.65 & 0.99945 & 0.98 \\
\hline
\end{tabular}

Nine samples with the same concentration were used to determine the accuracy and precision of the method and are presented in Table 4. The method's precision expressed as relative standard deviation (RSD) ranged from $0.42 \%$ to $0.44 \%$. The value of accuracy, expressed as the relative error $\left(\varepsilon_{\mathrm{r}}\right)$ obtained by OLS, was $1.87 \%$ for intra-day accuracy and $1.94 \%$ for inter-day accuracy. $\varepsilon_{\mathrm{r}}$ based on WLS was $0.84 \%$ for intra-day accuracy and $0.91 \%$ for inter-day accuracy. The calculated relative standard deviations (RSD) were $0.42 \%$ and $0.44 \%$ for intra-day and inter-day precision, respectively. The LOD and LOQ that were calculated by OLS were 0.0013 and $0.0038 \mathrm{mg} / \mathrm{mL}$, respectively. The LOD and LOQ obtained by WLS were $0.0012 \mathrm{mg} / \mathrm{mL}$ and $0.0037 \mathrm{mg} / \mathrm{mL}$, respectively.

Table 4. Accuracy and precision of the HPLC method.

\begin{tabular}{|c|c|c|c|}
\hline \multirow{2}{*}{$\begin{array}{l}\text { Concentration } \\
(\mathrm{mg} / \mathrm{mL})\end{array}$} & \multicolumn{2}{|c|}{$\begin{array}{c}\left.\text { Accuracy (Expressed as } \varepsilon_{\mathrm{r}}\right)(n=9) \\
\text { Acceptance Limit: } \% \mathrm{RE}<5 \%\end{array}$} & \multirow{2}{*}{$\begin{array}{l}\text { Precision (Expressed as RSD) } \\
\qquad(n=9) \\
\text { Acceptance Limit: RSD }<5 \%\end{array}$} \\
\hline & OLS $w_{i}=1$ & WLS $w_{i}=\frac{1}{y}$ & \\
\hline Intra-day 2.0 & $1.87 \%$ & $0.84 \%$ & 0.42 \\
\hline Inter-day2.0 & $1.94 \%$ & $0.91 \%$ & 0.44 \\
\hline
\end{tabular}

The developed and validated method was used for stability studies. For seven consecutive days, the HPLC analysis was performed and the content of OND was calculated. The fluctuation of the OND concentration in the sample during the storage time is presented in Figure 4.

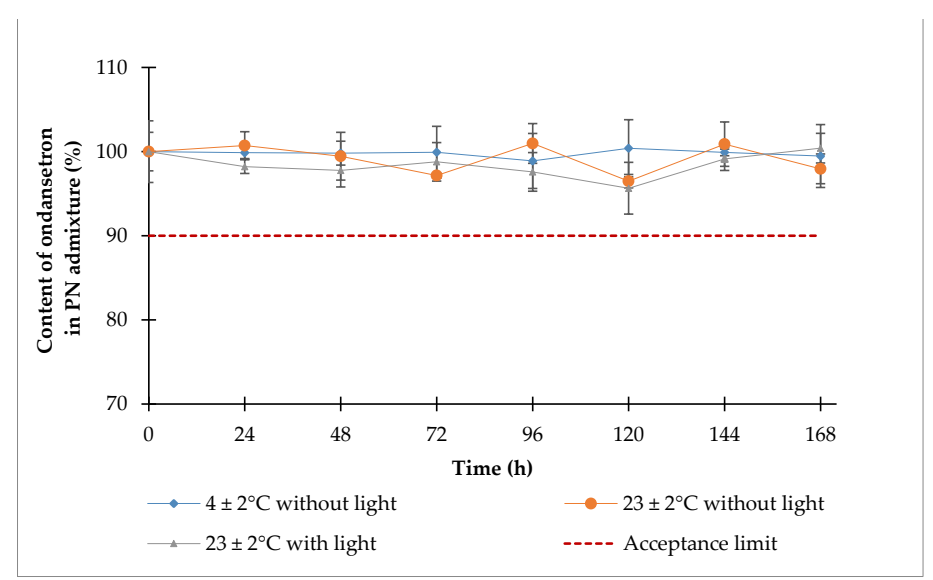

Figure 4. Content (\%) of OND during seven days of storage. 


\section{Discussion}

Many oncological patients need medical intervention to support their nutritional status. In this case, we used parenteral nutrition, which is one of the most widely used solutions. This type of therapy relies on intravenous delivery of nutritional, energetic, and regulatory ingredients in the form of an oil-in-water parenteral emulsion. Due to anticancer treatment, oncological patients often experience vomiting and nausea, negatively affecting their nutritional status and worsening the prognosis.

The solution may be the co-administration of parenteral nutrition with OND, a very well-known antiemetic drug. However, the co-administration of drugs with the parenteral nutrition admixture may cause an interaction manifested as emulsion creaming or coalescence, inactivation of the added drug, its precipitation, or degradation. For these reasons, it is essential to assess the physicochemical properties of the PN admixture after combination with the selected drug and to determine the drug stability in such intravenous emulsions. This study aimed to develop and validate the HPLC method for the determination of OND in Lipoflex special, one of the most popular and globally used PN admixtures. The developed and validated HPLC method was used for assessing the OND stability in PN admixture during the seven-day storage in different conditions.

The analysis of physicochemical properties of PN admixture, with and without OND, confirmed that Lipoflex special and Lipoflex special containing OND upon sample preparation and after the seventh day of storage met the requirement for parenteral drugs. PN admixture is a submicron lipid emulsion and is characterized by its thermodynamic instability. The oil-in-water emulsion is also a dynamic system, and it is sensitive to the alteration in the composition as well as external factors (temperature and light exposure). The zeta potential is the potential difference between the dispersion medium and the stationary layer of fluid attached to the particle, which allows evaluation of the strength of electrostatic interactions between particles in a PN admixture. The zeta potential depends on the electrolyte concentration and the $\mathrm{pH}$ of the sample. The $\mathrm{pH}$ changes may evidence the acid-based changes in the solution. The differences in zeta potential and osmolality observed upon OND addition are probably the consequence of the OND influence on the acidic properties of PN admixture. This effect is stabilized during storage, which is a reason observed seventh-day values of parameters mentioned above were similar to the reference sample.

Due to the physical properties of PN admixtures in the form of lipid emulsion, direct injection into the chromatographic column was impossible. Before the HPLC assay, the sample preparation procedure was developed and optimized. To break up the lipid emulsion, $n$-hexane, as an organic solvent, was used. Then, samples were shaken and centrifuged. Based on the recovery factor of OND, the best preparation parameters were chosen: $3.0 \mathrm{~mL}$ of Lipoflex special mixed with $3.0 \mathrm{~mL}$ of n-hexane, shaken, and centrifuged for 15 and $30 \mathrm{~min}$, respectively (Table 2).

The forced degradation studies confirmed that the used HPLC method was appropriate for the OND analysis in the PN admixtures. The possible degradation products or ingredients of the PN admixture would be separated from the OND peak and would not interfere with the OND signal (Figures 2 and 3). The stress sensitivity of both pure drug and drug in PN admixture is confirmed by other studies. OND is susceptible to oxidation and acid/basic hydrolysis, while it remains insensitive to decomposition under the influence of temperature at the boiling point [23,31].

The analysis of homoscedasticity of the data demonstrates that the better model for calculated linearity of the relationship between OND concentration and detector response is WLS rather than OLS. The best fit was obtained for weight $\frac{1}{y}$, which was used for further calculations. Similar conclusions were reached when validating an HPLC method to analyze ampicillin in PN admixtures [18]. The proposed HPLC method for the determination of OND in PN admixture is selective, precise, accurate, and linear and can be used for assessing the stability test of the studied drug. 
As demonstrated from the results of the stability studies, OND decomposed during storage regardless of conditions. The observed decrease in the OND content was similar for all tested samples and did not exceed 5\% throughout the test period (seven days). According to generally accepted standards, the decrease in the drug content during storage should not exceed $10 \%$, so OND shows adequate stability in Lipoflex special. OND stored in infusion fluids shows a similar stability. Casto [37] conducted stability studies of OND stored in normal saline and $5 \%$ dextrose at $-20{ }^{\circ} \mathrm{C}$ for up to three months, at $4{ }^{\circ} \mathrm{C}$ for up to two weeks, or at $22-25^{\circ} \mathrm{C}$ for two days, and various combinations of these conditions. The OND concentration in each solution, regardless of storage conditions, remained above $90 \%$. Moreover, Ringer injection [38] was found compatible with OND for 14 days at ambient temperature. All of these data prove stability of OND in different parenteral injection. Our results confirm the lack of influence of the mixture components (amino acids, electrolytes) on the accelerated degradation of the drug.

\section{Conclusions}

Lipoflex special ready-to-use PN admixture meets the requirements of intravenous oil-in-water emulsions, both upon preparation (activation) and after seven days of storage. Similarly, fulfilment of the requirements was observed for Lipoflex special containing OND in the daily dose.

The proposed HPLC method and the sample preparation procedure were suitable for the OND analysis in the PN admixture. The HPLC method proves to be selective and linear in the range of 0.0066 to $0.04 \mathrm{mg} / \mathrm{mL}$, precise ( $\mathrm{RSD}=0.42 \%-0.44 \%$ ), and accurate $\left(\varepsilon_{\mathrm{r}}=0.84-1.94 \%\right)$. A validated HPLC method was used to determine the stability of OND during storage under various conditions, such as exposure to sunlight and temperature. It was found that the decomposition of OND during the seven-day storage did not exceed $5 \%$ and was not dependent on external factors. Based on the conducted research, it is recommended to add OND in a dose of $32 \mathrm{mg}$ to Lipoflex special $1250 \mathrm{~mL}$, and it is possible to store such an admixture for seven days.

Author Contributions: Conceptualization, S.T. and M.S.; data curation, S.T.; formal analysis, V.R. and M.S.; funding acquisition, A.J.; investigation, S.T.; methodology, S.T., V.R. and M.S.; project administration, S.T. and A.J.; resources, A.J.; software, M.S.; supervision, M.S.; validation, S.T. and M.S.; visualization, M.S.; writing_original draft, S.T.; writing—review \& editing, A.J. and M.S. All authors have read and agreed to the published version of the manuscript.

Funding: This research received no external funding.

Institutional Review Board Statement: Not applicable.

Informed Consent Statement: Not applicable.

Data Availability Statement: The data presented in this study are available on request from the corresponding author.

Conflicts of Interest: The authors declare no conflict of interest.

\section{References}

1. Verheij, M.H.P.; Thompson, A.J.; Van Muijlwijk-Koezen, J.E.; Lummis, S.C.R.; Leurs, R.; De Esch, I.J.P. Design, Synthesis, and Structure-Activity Relationships of Highly Potent 5-HT3Receptor Ligands. J. Med. Chem. 2012, 55, 8603-8614. [CrossRef]

2. Gregory, R.E.; Ettinger, D.S. 5-HT3 Receptor Antagonists for the Prevention of Chemotherapy-Induced Nausea and Vomiting. Drugs 1998, 55, 173-189. [CrossRef]

3. Gan, T.J. Selective serotonin 5-HT3 receptor antagonists for postoperative nausea and vomiting: Are they all the same? CNS Drugs 2005, 19, 225-238. [CrossRef] [PubMed]

4. Bozzetti, F.; Arends, J.; Lundholm, K.; Micklewright, A.; Zurcher, G.; Muscaritoli, M. ESPEN Guidelines on Parenteral Nutrition: Non-surgical oncology. Clin. Nutr. 2009, 28, 445-454. [CrossRef] [PubMed]

5. Volkert, D.; Beck, A.M.; Cederholm, T.; Cruz-Jentoft, A.; Goisser, S.; Hooper, L.; Kiesswetter, E.; Maggio, M.; Raynaud-Simon, A.; Sieber, C.C.; et al. ESPEN guideline on clinical nutrition and hydration in geriatrics. Clin. Nutr. 2019, 38, 10-47. [CrossRef]

6. Fekadu, T.; Teweldemedhin, M.; Esrael, E.; Asgedom, S.W. Prevalence of intravenous medication administration errors: A cross-sectional study. Integr. Pharm. Res. Pr. 2017, 6, 47-51. [CrossRef] 
7. Vazquez, R.; Rotival, R.; Calvez, S.; Hoang, M.-D.; Graffard, H.; Guyon, F.; Do, B. Stability Indicating Assay Method on Vitamins: Application to their Stability Study in Parenteral Nutrition Admixtures. Chromatographia 2009, 69, 629-635. [CrossRef]

8. Ribeiro, D.O.; Pinto, D.C.; Lima, L.M.T.R.; Volpato, N.M.; Cabral, L.M.; De Sousa, V.P. Chemical stability study of vitamins thiamine, riboflavin, pyridoxine and ascorbic acid in parenteral nutrition for neonatal use. Nutr. J. 2011, 10, 47. [CrossRef]

9. Allwood, M.; Martin, H. Stability of cocarboxylase in parenteral nutrition mixturesstored in multilayer bags. Clin. Nutr. 1998, 17, 231-234. [CrossRef]

10. Allwood, M.; Martin, H. The photodegradation of vitamins A and E in parenteral nutrition mixtures during infusion. Clin. Nutr. 2000, 19, 339-342. [CrossRef]

11. Gibbons, E.; Allwood, M.C.; Neal, T.; Hardy, G. Degradation of dehydroascorbic acid in parenteral nutrition mixtures. J. Pharm. Biomed. Anal. 2001, 25, 605-611. [CrossRef]

12. Stawny, M.; Gostyńska, A.; Olijarczyk, R.; Jelińska, A.; Ogrodowczyk, M. Stability of high-dose thiamine in parenteral nutrition for treatment of patients with Wernicke's encephalopathy. Clin. Nutr. 2020, 39, 2929-2932. [CrossRef] [PubMed]

13. Baumgartner, T.G.; Henderson, G.N.; Fox, J.; Gondi, U. Stability of ranitidine and thiamine in parenteral nutrition solutions. Nutrition 1997, 13, 547-553. [CrossRef]

14. Stawny, M.; Gostyńska, A.; Olijarczyk, R.; Dettlaff, K.; Jelińska, A.; Ogrodowczyk, M. Stability studies of parenteral nutrition with a high dose of vitamin C. J. Oncol. Pharm. Pr. 2020, 26, 1894-1902. [CrossRef]

15. Tomczak, S.; Stawny, M.; Dettlaff, K.; Kieliszek, M.; Słomińska, D.; Jelińska, A. Physicochemical Compatibility and Stability of Linezolid with Parenteral Nutrition. Molecules 2019, 24, 1242. [CrossRef] [PubMed]

16. Iqbal, M.S.; Bahari, M.B.; Darwis, Y.; Venkatesh, G.; Gillani, S.W.; Khan, A.H.; Sheshala, R. A RP-HPLC-UV Method with Solid Phase Extraction for Determination of Cefepime in Total Nutrient Admixtures: Application to Stability Studies. Curr. Pharm. Anal. 2012, 8, 68-74. [CrossRef]

17. Wade, C.S.; Lampasona, V.; Mullins, R.E.; Parks, R.B. Stability of ceftazidime and amino acids in parenteral nutrient solutions. Am. J. Heal. Pharm. 1991, 48, 1515-1519. [CrossRef]

18. Stawny, M.; Gostyńska, A.; Dettlaff, K.; Jelińska, A.; Kościelniak, M.; Ogrodowczyk, M. Development, Validation, and Stability Assessment Application of RP-HPLC-DAD Method for Quantification of Ampicillin in Total Parenteral Nutrition Admixtures. Antibiotics 2019, 8, 268. [CrossRef]

19. Gostyńska, A.; Stawny, M.; Dettlaff, K.; Jelińska, A. The Interactions between Ciprofloxacin and Parenteral Nutrition Admixtures. Pharmaceutics 2019, 12, 27. [CrossRef]

20. Raza, A.; Ijaz, A.S.; Rehman, A.U.; Rasheed, U. Spectrophotometric Determination of Ondansetron Hydrochloride in Pharmaceutical Bulk and Dosage Forms. J. Chin. Chem. Soc. 2007, 54, 223-227. [CrossRef]

21. Estan-Cerezo, G.; Matoses-Chirivella, C.; Soriano-Irigaray, L.; Murcia-López, A.C.; Rodríguez-Lucena, F.J.; Navarro-Ruiz, A. Stability and compatibility of ondansetron with haloperidol in parenteral admixtures. Eur. J. Hosp. Pharm. 2017, 25, 200-203. [CrossRef] [PubMed]

22. Chong, Y.E.; Chiang, M.; Deshpande, K.; Haroutounian, S.; Kagan, L.; Lee, J.B. Simultaneous quantification of ondansetron and tariquidar in rat and human plasma using a high performance liquid chromatography-ultraviolet method. Biomed. Chromatogr. 2019, 33, e4653. [CrossRef] [PubMed]

23. Simar, J.; Godet, M.; Hecq, J.-D.; Closset, M.; Gillet, P.; Langhendries, C.; Bihin, B.; Jamart, J.; Galanti, L. Long-term stability of dexamethasone and alizapride or ondansetron in sodium chloride $0.9 \%$ polyolefin bag at $5 \pm 3{ }^{\circ} \mathrm{C}$. Ann. Pharm. Françaises 2017, 75, 30-39. [CrossRef]

24. Chen, F.-C.; Wang, L.-H.; Guo, J.; Shi, X.-Y.; Fang, B.-X. Simultaneous Determination of Dexamethasone, Ondansetron, Granisetron, Tropisetron, and Azasetron in Infusion Samples by HPLC with DAD Detection. J. Anal. Methods Chem. 2017, 2017, 1-7. [CrossRef]

25. Gaudette, F.; Bédard, D.; Kwan, C.; Frouni, I.; Hamadjida, A.; Beaudry, F.; Huot, P. Highly sensitive HPLC-MS/MS assay for the quantitation of ondansetron in rat plasma and rat brain tissue homogenate following administration of a very low subcutaneous dose. J. Pharm. Biomed. Anal. 2019, 175, 112766. [CrossRef]

26. Al-Ghobashy, M.A.; Kamal, S.M.; El-Sayed, G.M.; Attia, A.K.; Nagy, M.; ElZeiny, A.; Elrakaiby, M.T.; Nooh, M.M.; Abbassi, M.; Aziz, R.K. Determination of voriconazole and co-administered drugs in plasma of pediatric cancer patients using UPLC-MS/MS: A key step towards personalized therapeutics. J. Chromatogr. B Anal. Technol. Biomed. Life Sci. 2018, 1092, 489-498. [CrossRef] [PubMed]

27. Quimby, J.M.; Lake, R.C.; Hansen, R.J.; Lunghofer, P.J.; Gustafson, D.L. Oral, subcutaneous, and intravenous pharmacokinetics of ondansetron in healthy cats. J. Vet. Pharmacol. Therap. 2014, 37, 348-353. [CrossRef]

28. Belal, F.F.; Sharaf El-Din, M.K.; Eid, M.I.; El-Gamal, R.M. Micellar HPLC method using monolithic column for the simultaneous determination of linezolid and rifampicin in pharmaceuticals and biological fluids. Anal. Methods 2013, 5, 6165. [CrossRef]

29. Dotsikas, Y.; Kousoulos, C.; Tsatsou, G.; Loukas, Y.L. Development and validation of a rapid 96-well format based liquidliquid extraction and liquid chromatography-tandem mass spectrometry analysis method for ondansetron in human plasma. $J$. Chromatogr. B Anal. Technol. Biomed. Life Sci. 2006, 836, 79-82. [CrossRef]

30. Kenward, H.; Elliott, J.; Lee, T.; Pelligand, L. Anti-nausea effects and pharmacokinetics of ondansetron, maropitant and metoclopramide in a low-dose cisplatin model of nausea and vomiting in the dog: A blinded crossover study. BMC Vet. Res. 2017, 13, 1-12. [CrossRef] [PubMed] 
31. Espinosa-Bosch, M.; Sanchez-Rojas, F.; Bosch-Ojeda, C. Stability of mixtures of ondansetron and haloperidol stored in infusors at different temperatures. Eur. J. Hosp. Pharm. 2018, 25, e134-e138. [CrossRef] [PubMed]

32. Kirkham, J.C.; Rutherford, E.T.; Cunningham, G.N.; Daneshmand, K.A.; Falls, A.L. Stability of ondansetron hydrochloride in a total parenteral nutrient admixture. Am. J. Heal. Pharm. 1995, 52, 1557-1558. [CrossRef]

33. Council of Europe European Pharmacopoeia 10th Edition I EDQM-European Directorate for the Quality of Medicines. Ondansetron Hydrochloride Dihydrate Monograph. Available online: https:/ /www.edqm.eu/en/european-pharmacopoeia-pheur-10th-edition. (accessed on 10 October 2020).

34. Tomczak, S.; Stawny, M.; Jelińska, A. Co-administration of drugs and parenteral nutrition: In vitro compatibility studies of loop diuretics for safer clinical practice. Pharmaceutics 2020, 12, 1092. [CrossRef] [PubMed]

35. Stawny, M.; Nadolna, M.; Jelińska, A. In vitro compatibility studies of vancomycin with ready-to-use parenteral nutrition admixtures for safer clinical practice. Clin. Nutr. 2019, 39, 2539-2546. [CrossRef] [PubMed]

36. European Medicines Agency. ICH Topic Q2(R1). In Validation of analytical procedures. In: Proceedings of the International Conference on Harmonization of Technical Requirements for Registration of Pharmaceuticals for Human Use; European Medicines Agency: Geneva, Switzerland, 1994. Available online: https:/ / www.ema.europa.eu/en/documents/scientific-guideline/ich-q-2-r1-validationanalytical-procedures-text-methodology-step-5_en.pdf. (accessed on 12 October 2020).

37. Casto, D.T. Stability of ondansetron stored in polypropylene syringes. Ann. Pharmacother. 1994, 28, 712-714. [CrossRef]

38. Graham, C.L.; Dukes, G.E.; Kao, C.-F.; Bertch, J.M.; Hak, L.J. Stability of Ondansetron in Large-Volume Parenteral Solutions. Ann. Pharmacother. 1992, 26, 768-771. [CrossRef] [PubMed] 